\title{
Late Effects of Radiation on Skeletal Muscle: An Open Field of Research
}

\author{
Wilson Viana1*, Daniel Lambertz², Edvane Borges², Jonathan Melo3, \\ Karla Lambertz ${ }^{4}$, Ademir Amaral ${ }^{2}$ \\ ${ }^{1}$ Núcleo de Educação Física e Ciências do Esporte/Centro Acadêmico de Vitória, CAV/Universidade Federal de \\ Pernambuco (UFPE), Vitória de Santo Antão, Brazil \\ ${ }^{2}$ Departamento de Energia Nuclear, DEN/Centro de Tecnologia e Geociencias, CTG/Universidade Federal de \\ Pernambuco (UFPE), Recife, Brazil \\ ${ }^{3}$ Instituto Federal de Educação, Ciência e Tecnologia de Pernambuco, IFPE, Recife , Brazil \\ ${ }^{4}$ Departamento de Fisioterapia, DEFISIO/Centro de Ciências da Saúde, Universidade Federal de Pernambuco \\ (UFPE), Recife, Brazil \\ Email: "wilsonvcm@gmail.com
}

Received 16 July 2015; accepted 24 August 2015; published 27 August 2015

Copyright $@ 2015$ by authors and Scientific Research Publishing Inc.

This work is licensed under the Creative Commons Attribution International License (CC BY).

http://creativecommons.org/licenses/by/4.0/

(c) () Open Access

\begin{abstract}
This paper presents an overview of the state of the art about the late effects of ionizing radiation on skeletal muscle, helping new research and showing unexplored areas. For this, it was evaluated the interest reported by the scientific literature regarding the late effects in skeletal muscle resulting from exposure to ionizing radiation. Original and experimental papers mainly containing the key expressions "ionizing radiation" and "effects on skeletal muscle" were searched in computerized databases, and published in any language. Only 33 papers matched the search criteria. Analyzing the investigated radioinduced biological effects in those contributions, four topics were identified as being of major interest: 1) alterations in cellular metabolism and protein degradation; 2) repercussions on satellite cells; 3) formation of fibrosis and muscle atrophy; 4) tissue regeneration. It was verified that no study evaluated possible late effects related to either morphology or properties of skeletal muscles after an exposure to ionizing radiation. Several aspects do not make possible a successful replication; all experiments of eligible group of articles are discussed, such as, lack of raw data, use of no sound methodology and inappropriate statistical technique. Briefly, the subject of this review is an open field of research.
\end{abstract}

\section{Keywords}

Ionizing Radiation, Radiation Therapy, Skeletal Muscle, Complications, Late

\footnotetext{
${ }^{*}$ Corresponding author.
}

How to cite this paper: Viana, W., Lambertz, D., Borges, E., Melo, J., Lambertz, K. and Amaral, A. (2015) Late Effects of Radiation on Skeletal Muscle: An Open Field of Research. J. Biomedical Science and Engineering, 8, 555-570. 


\section{Introduction}

Radiotherapy (RT) is one of the most important treatment options in cancer therapy, and most patients $(50 \%$ $70 \%$ ) undergo this treatment during the course of the disease [1]. Irradiation protocols depend on several factors such as: the type, extent and location of the tumor, the tolerance of healthy tissues and the general health of the patient, which can result in acute or late side effects [2] [3]. In parallel, the severity of these effects is directly related to the quality of radiation and the dose-fractionation protocol [4].

As RT can produce late adverse effects, special attention is taken when this kind of treatment is applied in childhood and a careful follow-up is very important [5]. For example, in developed countries, children and teenagers are the most affected by leukemia, followed by tumors of the central nervous system lymphomas and, when ionizing radiation is part of their treatment [6], those patients usually present musculoskeletal disorders as the more common late sequels [7]. These effects act directly on skeletal muscle, which is a tissue that maintains a high degree of phenotypic plasticity throughout the lifetime of the individual, enabling adaptive responses as a function of the stimulus delivered [8].

Skeletal muscle of vertebrates (Figure 1) is a tissue consists of individual muscle fibers cylindrical heterogeneous, diversified in shape, size and contractile protein content [9]. The muscle fiber is the structural unit of the skeletal muscle with a thickness ranging from 10 to 100 micrometers (microns) and length 10 to $50 \mathrm{~cm}$. The muscle is coated for connective tissue present also in other body structures, which provide the organization of the muscle fibers in three different groups: endomysium, perimysium and epimysium [10].

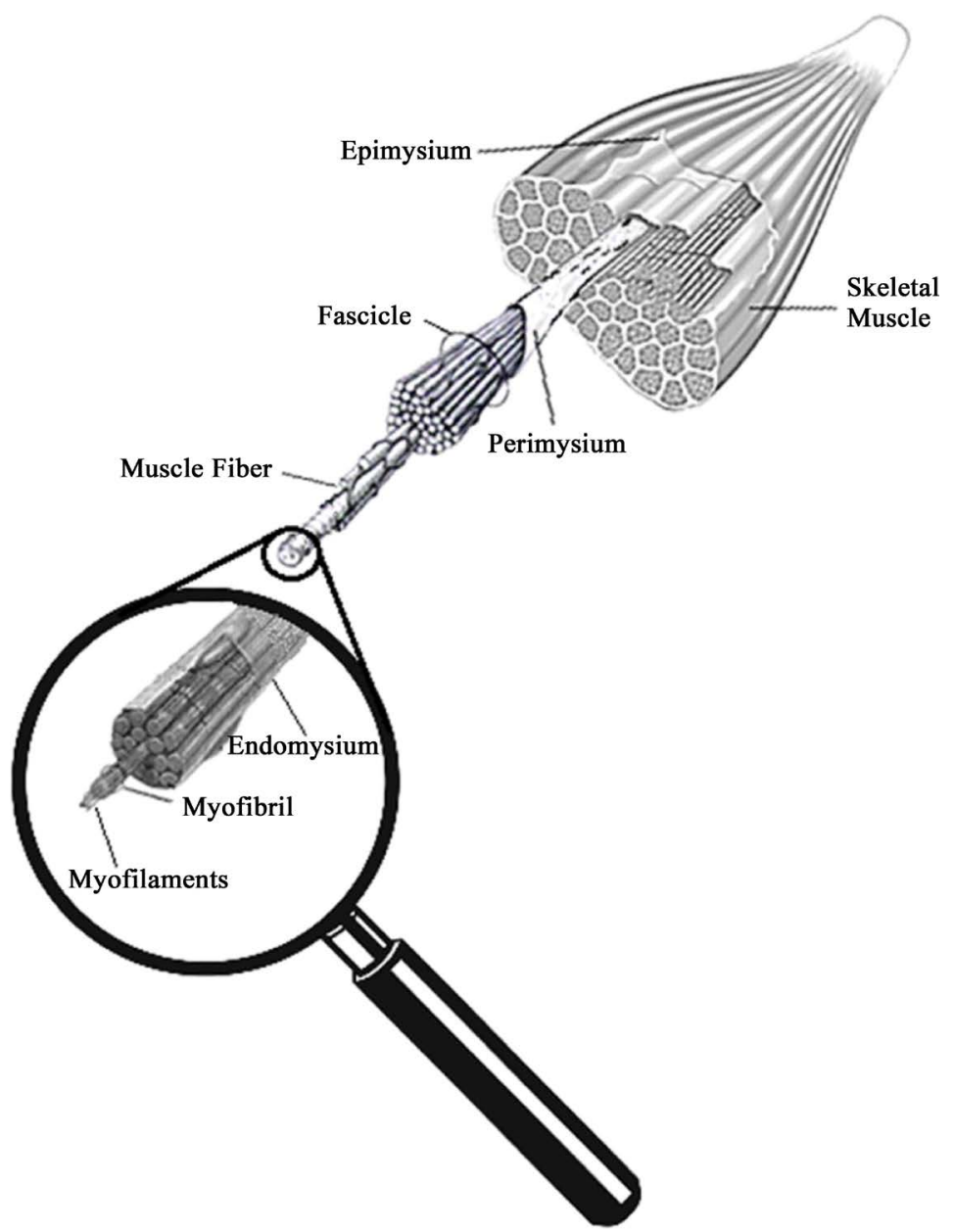

Figure 1. Different connective tissues are identified in muscle. The epimisium involves the muscle belly, the perimysium covers the fasciculi. Each muscle fiber containing myofibrils is surrounded by the endomysium. 
Although the different connective tissues are described separately, they are interlaced in such a way that they can be considered as a single continuous lamina of tissue that covers the muscle, helping to generate passive tension and resistance to stretching, helping the muscle to recover its shape and transferring contractile force to the tendon [10].

It should be highlighted that in the period of growth the proper tropism and muscle metabolism are essential to provide incentives for physical growth and adequate motor development up to adulthood [11].

Skeletal muscle represents approximately $40 \%$ of total body mass and has significant capacity to oxidation of substrates, besides a fundamental role in the body metabolism in either health or illness [12]. Some studies have shown that this tissue suffers from radiation effects by direct action on their cellular structure, reflecting in the amount or type of muscle proteins [13]-[16]. Olive and colleagues (1995) demonstrate that gamma radiation induces cell death in muscle with morphological characteristics of apoptosis. In turn, Jurdana (2008) affirms that radiation affects muscle satellite cells, impairing their activation, proliferation and differentiation, as well as interfering in membrane permeability and affecting sodium and potassium pump [17].

In this way, although one realizes that ionizing radiation can have adverse effects on patients, there are few investigations about how radiation can directly affect skeletal muscle morphologically and functionally.

In this context, this review was aimed to evaluate the interest reported in the scientific literature concerning late effects on skeletal muscle as a result of exposure to ionizing radiation.

\section{Search Methodology}

Studies associated with this theme were searched in computerized internet databases available until May 2015. The sources of information were accessed in the following databases:

- Cumulative Index to Nursing and Allied Health Literature(CINAHL);

- Scientific Electronic Library Online (SciELO);

- Medical Literature Analysis and Retrieval System On-line (Medline/Pubmed).

It was used the logical operators "AND", "OR" for combining descriptors and terms employed for searching. Thus, the following key expression was used: "ionizing radiation, radiotherapy, damage, skeletal muscle", indexed in MeSH.

The inclusion criteria were papers treating effects on skeletal muscle associated to exposure to ionizing radiation, being considered only original experimental studies. By this search procedure, 402 potentially eligible papers were identified.

After the first triage, this study focused on reports that had the key terms in their titles. As a result, 69 publications were selected. However, from those selected texts, 36 did not present neither abstract nor full text. Thus, 33 articles were finally considered eligible for the second phase (MEDLINE $=32$; and CINAHL $=01$ ), which consisted of the reading of the abstracts and, when available, the evaluation of its full text.

Figure 2 summarizes the flowchart employed for triage and final selection of works to be discussed in the context of this review.

The following topics were particularly considered for evaluating the selected articles:

- Studied subjects (animals/humans);

- Sampling (randomization);

- Radiation and dose levels;

- Irradiated target (part of the body irradiated);

- Statistical analyses;

- Parameters assessed.

\section{Results}

As primarily result, temporal lacunae were found between 1954-1974 and 2000-2009, in which none study concerning "ionizing radiation" and "skeletal muscle" appears in the investigated databases.

From 33 studies included in this review, only six [14] [18]-[22] mentioned that they conducted randomization of samples, while other three studies did not specify the type of radiation applied in their experiments [23]-[25].

On the other hand, one study [26] did not report the dose level, and two others did not report the part of the body that was exposed to radiation [26] [27].

Regarding the statistical analyses, only thirteen out of the 33 selected studies specified which tests were used 


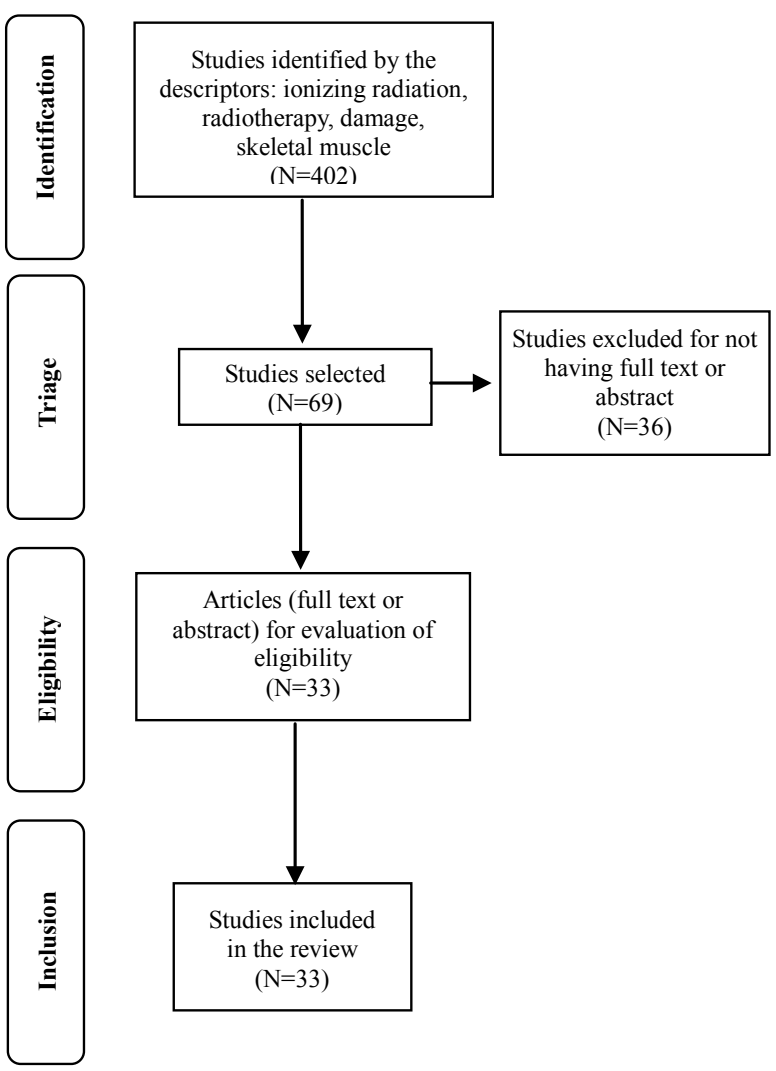

Figure 2. Flowchart of selection of studies included in the review.

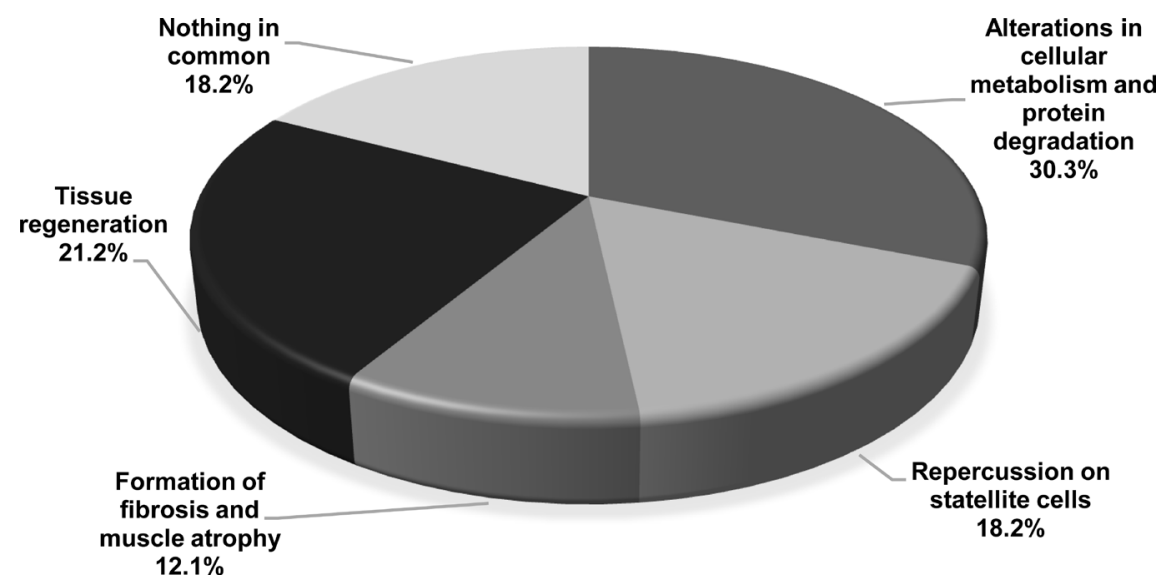

Figure 3. Percentage contribution of each group relative to the total number of studies included in this review.

in inferential decisions about the results [18]-[20] [28]-[37].

Concerning the kind of analytical methodology employed, four studies did not mention how their results were technically achieved [27] [38]-[40]. Among these studies, one did not even mention any evaluated parameters [38].

In terms of radio induced biological effects on skeletal muscles, from the selected articles, four axes of researches were identified: 1) alterations in cellular metabolism and protein degradation (Table 1); 2) repercussions on satellite cells (Table 2); 3) formation of fibrosis and muscle atrophy (Table 3); 4) tissue regeneration (Table 4).

Figure 3 compares the percentage contribution of the selected articles for each topic. 


\subsection{Alterations in Metabolism and Protein Degradation}

Table 1 presents the studies that investigated changes on cellular metabolism and muscle protein degradation.

Gerstner and colleagues (1953) comparatively studied the effects of radiation in the muscles of rabbits (warmblooded animals) and isolated muscles from frogs (cold-blooded animals) exposed to high dose rates of X-rays. The muscles of frog with doses above 100,000 R (870 Gy) quickly showed fatigue presenting contracture, prolonged relaxation, reduced amplitude of contraction for heavy loads (50 g) and histological changes, 8 hours after exposure. These changes consisted of hyalinization and breaking up of single muscle fibers or small groups of fibers, nuclei of muscle cells were either absent or showed karyorrhexis, and the sarcolemma was destroyed in the degenerated areas. In turn, muscles of rabbits exposed to 72,000 R (626.4 Gy) exhibited a progressive and gradual impairment of the function with complete disability 24 hours after irradiation, followed by severe histological changes, such as swollen muscle fibers and hyalinized with loss of striations, many broken fibers with loss of nuclei and considerable numbers of polymorph nuclear leukocytes present.

In another research performed with rabbits exposed to $1130 \mathrm{R}$ (9.83 Gy) and $1300 \mathrm{R}$ (11.3 Gy), Khan and coworkers (1974) [14] observed local increase of glycogen in intact fibers, and damages in the muscle fibers and micro vasculature. These effects were noticed from the first 24 hours until the $40^{\text {th }}$ day after irradiation. This effect was still seen until the 40th day after exposure.

With the same perspective, Ahlersova and colleagues (1981) [41] used in their study Wistar rats irradiated with a whole body X-ray dose of 2.39 Gy in the fasting at night before the irradiation, acknowledging changes in carbohydrate metabolism and reduced muscle glycogen 6 hours after irradiation, with subsequent increase in the $3^{\text {rd }}$ and $14^{\text {th }}$ days. The kinetic of the alterations of the glycogen produced by fasting in skeletal and cardiac muscle was similar to the changes caused by irradiation, especially during the first week.

In turn, degradation of titin and nebulin protein was observed by Horowits and coworkers (1986). In study [23] in rabbits isolating the psoas muscle and irradiated with $1.5 \mathrm{Mrad}(15,000 \mathrm{~Gy})$. The capacity of the muscle cells to generate passive and active tension was reduced due to axial misalignment of the thick filaments that are apparently maintained centered in the sarcomere by titin and/or nebulin causing reduction of elastic properties of muscle.

Schwenen and colleagues (1989) [39] also investigated muscle proteins and found that after exposure on hind limb of mice to $15 \mathrm{~Gy}$ of gamma radiation caused an increase in the release of amino acids, especially alanine, glutamine and others not metabolized in muscle. These researchers claim that their findings confirmed the hypothesis that the increased availability of amino acids is a result of the increased protein degradation in skeletal muscle, starting immediately after irradiation. This perturbation induced by radiation in protein metabolism may be a pathogenic factor in the etiology of the myopathy of the radiation.

On the other hand, Voĭtsitskiı̌ and colleagues (1990) found changes in the sarcoplasmatic reticulum membrane due to enzymatic changes of $\mathrm{Ca}^{2+}$-ATPase in muscles of hind legs of rabbits irradiated with a dose of 0.21 $\mathrm{C} \cdot \mathrm{kg}^{-1}$. Subsequent studies [38] [42] also observed changes in the sarcoplasmic reticulum membrane due to the enzyme $\mathrm{Ca}^{2+}$-ATPase. The authors argued that the decrease in the concentration of $\mathrm{Ca}^{2+}$-ATPase was caused by a change in the enzyme microenvironment damaging lipid-protein interactions, essential for the functional activity of this enzyme and changes in molecular conformation of $\mathrm{Ca}^{2+}$-ATPase contribute to structural change of the membrane.

Other study [27] carried out analyses to measure the content of thiamin in skeletal muscle and liver pork, chicken and beef after gamma irradiation from a Cesium source with doses of 1.5, 3, 6 and $10 \mathrm{kGy}$, found a decrease of thiamine three times more in skeletal muscle, when compared with the liver. The thiamine content of the muscle was another aspect affected by gamma irradiation.

The study of Shtifman and coworkers [22] sought to investigate the effects of single whole-body low-dose high-energy proton irradiation as a model for solar particle event and low-dose high-charge and energy irradiation as a model for galactic cosmic rays on skeletal muscle physiology in adult $\mathrm{C} 57 \mathrm{Bl} / 6 \mathrm{~N}$ WT mice. The data indicated that proton and ${ }^{56} \mathrm{Fe}$-particle irradiation resulted in intra-myofiber alterations in $\mathrm{Ca}^{2+}$.

\subsection{Repercussions on Satellite Cells}

Table 2 shows the studies related to the repercussions of radiation on satellite cell.

Rosenblatt and Parry (1992) hypothesized that compensatory muscle hypertrophy of long extensor of the fingers (EDL), produced by the incapacitation of the synergistic tibialis anterior muscle, would be prevented if, be- 


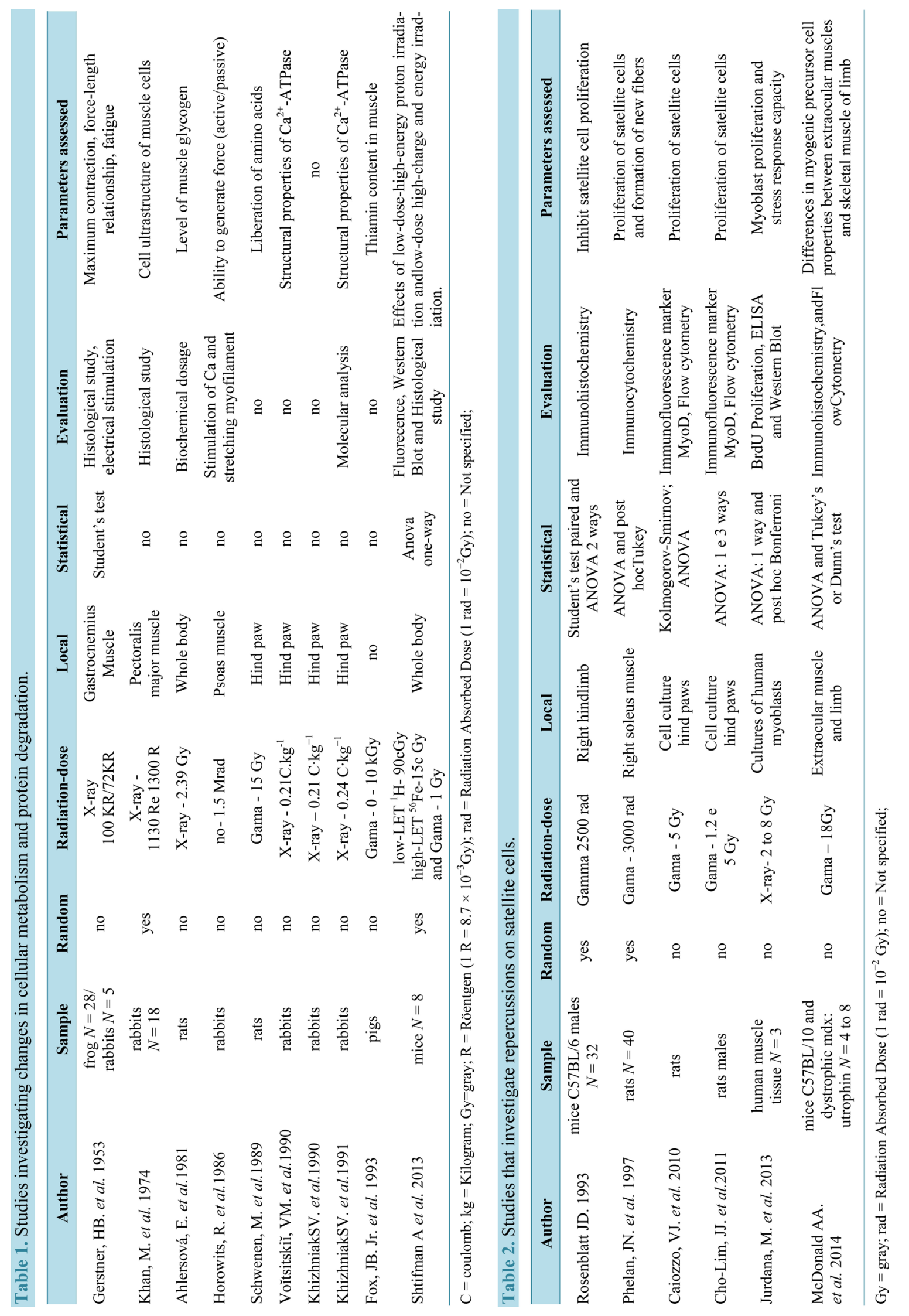


fore being overloaded, the EDL muscle was subjected to levels of ionizing radiation that are known to inhibit satellite cell proliferation. For this, right hindlimbs of mice were irradiated to a single dose Gamma 2500 rad (25 Gy) and tibialis anterior muscles were excised and discarded. The results clearly supported this hypothesis.

Within this same perspective, Phelan and coworkers (1997) irradiated male Wistar rats by a 137 Cesium source with $3000 \mathrm{rad}(30 \mathrm{~Gy})$ and pointed out that gamma irradiation prevented the compensatory hypertrophy and generation of muscle fibers. However, they also found that there was no decrease in the percentage of mature fibers, concluding that irradiation impairs the proliferation of satellite cells, impacting on the process of muscle hypertrophy.

In another study, Caiozzo and colleagues (2010) observed a reduction in the number of satellite cells in a study in which female rats of the Sprague-Dawley species were exposed to gamma radiation. This reduction was dependent of the applied dose ( 2 or $5 \mathrm{~Gy}$ ), reducing at about $50 \%$ and $70 \%$ respectively the number of cells. According to these authors, clinically relevant doses of gamma radiation produced significant elevations in oxidative stress, significantly reducing the levels of nitric oxide (NO) in satellite cells and can impair the proliferation in vitro.

Still investigating effects of radiation on NO levels in satellite cells on muscles, Cho Lim and colleagues (2011) removed the hind paws of male rats of the Sprague-Dawley species, and irradiated with doses of 1.2 and 5 Gy using a Cs-137 source. For this, two procedures were employed: addition of sodium nitro prusside-SNP (NO donor) and known mechanical stretching to increase NO levels in the cellular environment [43]. On the basis of this methodology, a significant increase of NO levels were reached resulting in the rescue of the proliferation of irradiated satellite cells. However, the mechanical stretching produced increased levels of NO more effective than SNP concluded that increasing the level of NO in irradiated satellite cells effectively is rescues their proliferation.

Jurdana and colleagues (2013) evaluated long-term effects of different doses of ionizing radiation on human skeletal muscle myoblast proliferation and stress response capacity in primary cell cultures. Human myoblasts were derived from satellite cells obtained from muscle tissue routinely discarded during orthopaedic operations on donor patients. Cells were irradiated with a dose rate of $2 \mathrm{~Gy} / \mathrm{min}$ with graded doses $(2-8 \mathrm{~Gy})$. Acute effects of radiation were studied by interleukin-6 (IL-6) release and stress response detected by the heat shock protein (HSP) level, while long-term effects were followed by proliferation capacity and cell death. Their results showed that myoblasts are sensitive to irradiation in terms of their proliferation capacity and capacity to secret IL-6.

MacDonald and coworkers (2014) [44] compared the properties of the precursor myogenic cells in extraocular muscle and limb muscles using mice $\mathrm{C} 57 \mathrm{BL} / 10$ and dystrophic mdx. It appears that irradiation disrupts the normal method of extraocular muscle remodeling, which react paradoxically to produce increased numbers of myogenic precursor cells, suggesting that the extraocular muscle contains myogenic precursor cell types resistant to 18 Gy gamma irradiation, allowing return to normal morphology 2 months post-irradiation.

\subsection{Fibrosis and Muscular Atrophy}

Table 3 presents studies that investigated the formation of fibrosis and atrophy processes consequences of irradiation.

Using acute gamma irradiation in pigs for simulating a nuclear accident, Lefaix and coworkers (1990) noticed, by biochemical analysis, a strong inflammatory reaction with the formation of fibrosis, in the first month after irradiation. The resulting muscle fibrosis was characterized by a high density of myofibroblasts and an inflammatory standard distribution of collagen types I, III, IV, laminin, fibronectin and fibrinogen. In another study [45], also in pigs, where posterior and outer portion of the thighs were gamma irradiated at doses ranging between 16 and 256 Gy of gamma radiation, was observed most desquamation of the skin and formation of fibrosis in muscles after 30 weeks.

Ibarrola and colleagues (1996) [46] evaluated the progression of the induced injury by irradiation for a period of 12 months in muscle of the rabbit iliac region, with gamma exposure of the skin with doses of 40 and $80 \mathrm{~Gy}$. Through magnetic resonance imaging, lesions were detected after 22 weeks from a group irradiated with 40 Gy and, earlier, at 17 weeks for the group with $80 \mathrm{~Gy}$. Their results pointed out the increase of muscle atrophy and the extent of injury with radiation dose.

In the context of this review, it was found only one clinical approach represented by the study performed by van Leeuwen-Segarceanu and colleagues (2012). They described the damages to the muscles and propose a pathophysiologic mechanism for muscle atrophy and weakness, from 12 patients with Hodgkin lymphoma treated 
with radiotherapy, between 1969 and 1998. The following tests were performed: dynamometry; ultrasound of the sternocleidomastoid, biceps, and antebrachial flexor muscles; and needle electromyography of the neck, deltoid, and ultrasono graphically affected arm muscles. Ten patients $(83 \%)$ presented neck complaints, mostly pain and muscle weakness. On clinical examination, neck flexors were more often affected than neck extensors. On ultrasound, the sternocleidomastoid was severely atrophic in eight patients.

\subsection{Tissue Regeneration}

Table 4 shows the studies dealing with the regeneration of muscle tissue.

Among the selected studies presented on the table above, the first one Popova and coworkers (1978) pointed out concern about the need to regain muscle after irradiation. Treatment with application of Laser for 10 days in removed muscles and irradiated with dose of $1000 \mathrm{R}(8.7 \mathrm{~Gy})$ of X-rays and then grafted, was able to stimulate the regeneration of injured muscle parts. The regeneration occurred not only in the periphery, but also within the muscle and resulted in the recovery of the capacity of contraction.

In another study [47], it was observed reduction of the post-traumatic effect of radiation in gastrocnemius muscle of rats, irradiated with doses of 20 to $30 \mathrm{~Gy}$ X-rays through an autograft of viscous mass consisting of muscle fiber pieces applied at the end of the muscle, which promoted the formation of differentiated muscle fibers and restoration of regenerative capacity.

Wirtz and colleagues (1982) searched to investigate effects of irradiation on regeneration in dystrophic mouse leg muscles. They irradiated mouse (strain Re 129) with a single dose of 20 Gy 10 days after birth, in such a way that only one leg was exposed to radiation. After irradiation, the development of satellite cells into regenerating muscle fibers appeared to be hampered. In animals of 17 days of age, i.e. 1 week after irradiation, many young regenerating muscle fibers were observed in the contralateral leg, whereas in the irradiated leg the empty spaces left by fiber necrosis were filled with fibrous tissue containing fibroblasts, macrophages and also myofibroblast-like cells.

A description of a dose-dependent effect on inhibition of muscle regeneration due to irradiation was performed by Gulati (1987) [48]. In this study, EDL were removed from rats and irradiated at a rate of 750 R.min ${ }^{-1}$ $\left(6.52 \mathrm{~Gy} \cdot \mathrm{min}^{-1}\right)$, and then transplanted to its place of origin. After transplantation, doses of $650 \mathrm{R}$ (5.65 Gy), $2000 \mathrm{R}(17.4 \mathrm{~Gy})$ and 10,000 R ( $87 \mathrm{~Gy})$ were administered. A similar pattern was observed for regeneration of non-irradiated and irradiated muscles with a dose of muscles $650 \mathrm{R}(5.65 \mathrm{~Gy}) \mathrm{X}$-ray where most of the myofibers suffered degeneration followed by regeneration from precursor satellite cells, which proliferated, differentiated into myoblasts and have fused to form myotubes and myofibers. However, in muscles exposed to $2000 \mathrm{R}$ (17.4 Gy) and 10,000 R (87 Gy), satellite cells remained undifferentiated and not merged to form myotubes.

With the objective of observing if muscle fiber growth can occur in the absence of satellite cell activity, Rosenblatt and Parry (1993) induced chronic overload of the right EDL muscle by removal of the synergist tibialis anterior muscle and reproductive sterilization of proliferative (satellite) cells by exposing to $25 \mathrm{~Gy}$ gamma irradiation. They conclude that changes in a muscle fiber's gene expression appears not to require the incorporation of new nuclei and occurs exclusively within the original myonuclei, whose function is unaffected by doses of irradiation the same as or exceeding that used in their study.

In order to observe the effects of radiation on dystrophic muscle of mdx mice at the age of 16 - 20 days, Granata and coworkers (1998) exposed soleus muscle to a single dose of $30 \mathrm{~Gy}$ gamma rays. At the age of 45,75 and 90 days, the transverse sections of the muscle belly were used for microscopic examination and found that irradiation appears to reduce the growth and regeneration of muscle fibers.

Unlike other studies, Wernig and colleagues (2000), in a program to increase the effects of myoblast implantation, used cultured cells and posteriorly implanted in the soleus muscle of rats previously irradiated with 16 Gy and found that the radiation increased the effectiveness of myoblast transplanted, promoting the proliferation of numerous fibers of small diameter. Six studies have no relationship to each other and are presented in Table $\mathbf{5}$.

Recent studies, such as Russell and Nadine [21] investigated the effect of radiation on muscles of the tongue associate with aging to determine whether aging altered the extent of radiation injury. In this study, thirty seven male Fisher 344/Brown Norway rats were irradiated with a dose of 22 Gy over two days equivalent to single fraction 16 Gy which is biological dose corresponding to $103 \mathrm{~Gy}$. Radiation was associated with a significant decrease in tongue force production and reduced speed of tongue muscle contraction. However, radiation treatment did not lead to muscle atrophy and fibrosis formation in the muscles of tongue and did not exacerbate atrophic changes observed with aging. 


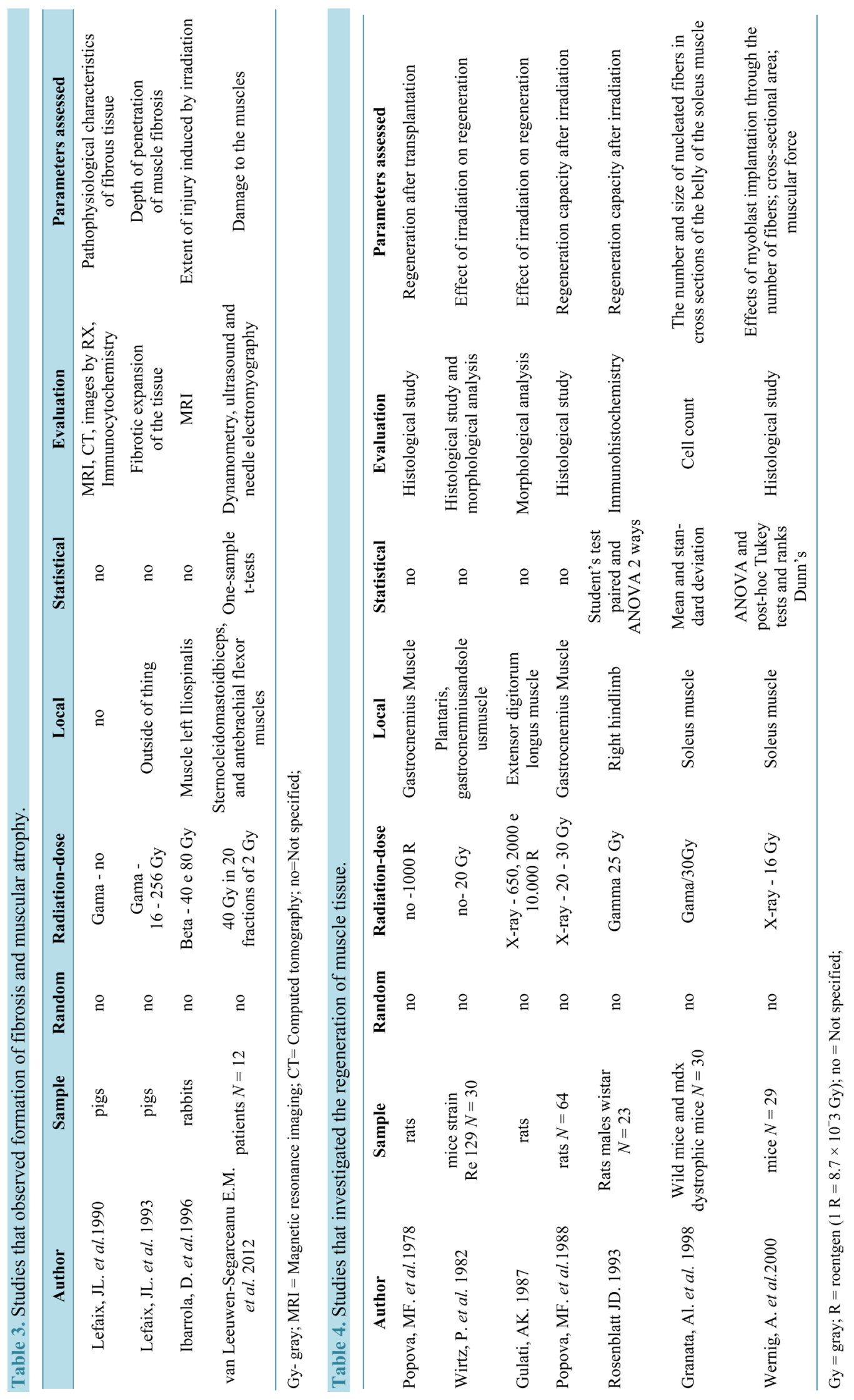




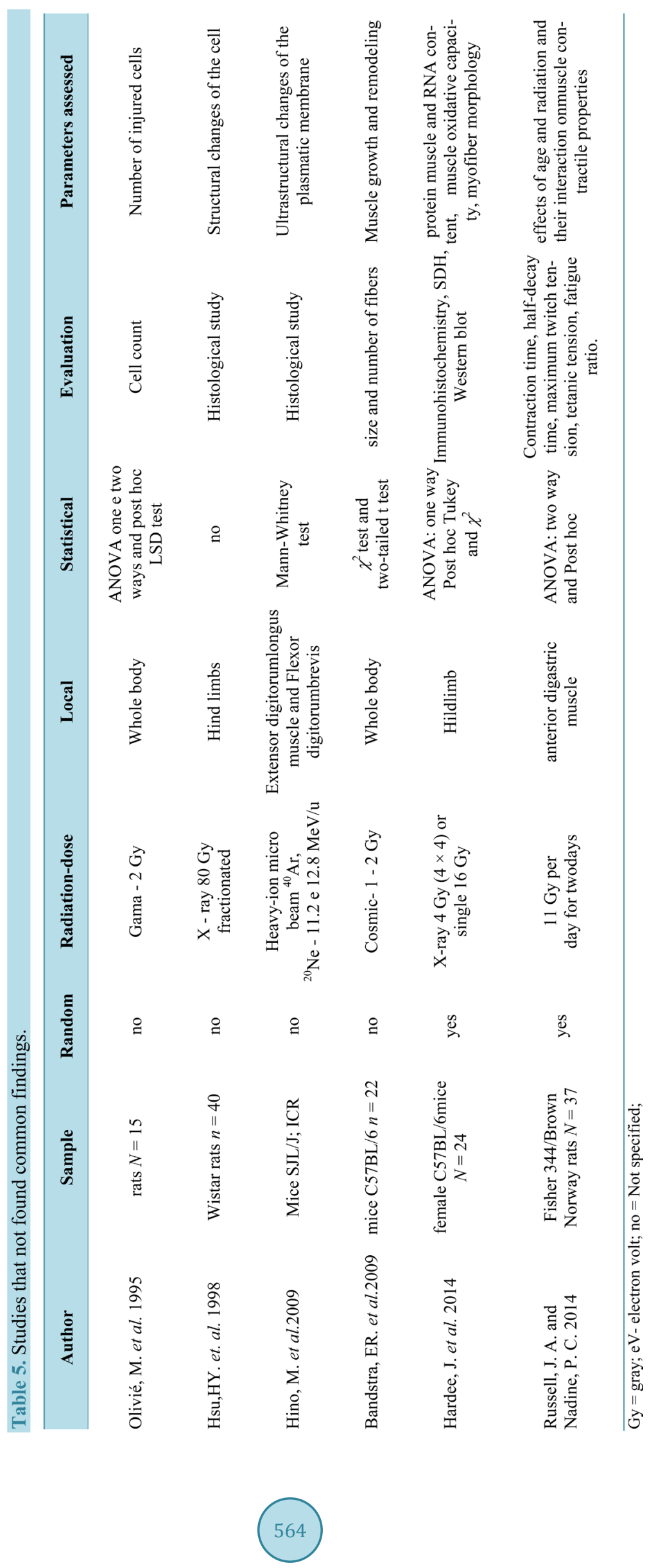


Another recent study [18] evaluated the effect of two clinically relevant radiation doses on the susceptibility of mouse skeletal muscle to remodeling. These authors hypothesized that radiation would induce muscle remodeling in a dose dependent manner and that glycolytic type IIB muscle fibers would be more susceptible to radiation-induced changes in size and distribution, when compared to more oxidative type IIA muscle fibers. Alterations in muscle morphology and regulatory signaling were examined in female C57BL/mouse tibialis anterior and gastrocnemius muscles after radiation doses that differed in total biological effective dose (BED). Results demonstrate that radiation dose differentially affects muscle remodeling, and these effects appear to be related to fiber type and oxidative metabolism.

Olivié and collaborators (1995) observed that gamma irradiation in developing muscles leads to cell death by apoptosis. Whereas Bandstra and coworkers (2009) stated that the radiation alters the distribution of myofibers, because they detected fewer small-diameter fibers in muscle irradiated, and an increase in the proportion of 2.9 times myofibers centrally nucleated, without clarifying the mechanism of these changes.

In the study of Hino and colleagues (2009), the structural integrity of the plasmatic membrane was affected by irradiation with heavy ion beams, ${ }^{40} \mathrm{Ar}(11.2 \mathrm{MeV} / \mathrm{u})$ and ${ }^{20} \mathrm{Ne}(12.8 \mathrm{MeV} / \mathrm{u})$, the occurrence of irregular protrusions on the plasmatic membrane (invaginations) and disruption of sarcomeres, was observed, they concluded that the dysferlin protein is responsible for fusion of the plasmatic membrane and this insufficiency causes defects on its surface.

Ultimately, muscle injuries in the hind paws of male Wistar rats after exposure to high doses of radiation was evaluated by biopsy by Hsu and coworkers (1998) [49], both paws were exposed to X-ray dose of 80 Gy in 40 fractions of $2 \mathrm{~Gy}$. The irradiated gastrocnemius muscle exhibited progressive changes, which started immediately after the conclusion of the exposures, characterized by hemorrhage, lymphocytic infiltration and vascular destruction. Until 12 months after the final exposure, no recovery of muscle tissue was observed.

\section{Discussion}

From all studies spotted by the search criteria employed in this review, just only $8 \%$ explored some effects of ionizing radiation on the Skeletal muscle. Their methodological aspects are presented below.

\subsection{Studied Subjects (Animals/Humans)}

Concerning especially animal model, rats and mice are used in the major part of experiments due to the ease in handling and brevity of the observation of the effects, both immediate and delayed, and physiological similarity to humans [50] [51]. Only one study used cells of humans. In terms of sample size, only 18 studies reported the number of subjects.

\subsection{Sampling (Randomization)}

Based on the principle that randomization as the best way to avoid bias, only six studies [14] [18]-[22] performed their investigation taking into account the randomization of samples.

\subsection{Radiation and Dose Levels}

It was also observed that gamma and X-rays were the types of radiation the most used in the studies evaluated, probably because these radiations are the most widely used in medical applications, especially in radiotherapy [2]. For small radiation fields, such as for specific muscle, the dose levels delivered reached $870 \mathrm{~Gy}$, while for whole body irradiation doses were lower, going to $15 \mathrm{~Gy}$.

\subsection{Irradiated Target}

In the studies reported by this review, different parts of the animal body were irradiated, from one muscle to the whole body. .

\subsection{Statistical Analyses}

In terms of statistical tests used, several studies employed appropriate tests to the proposed objectives [18]-[20] [22] [28]-[31] [34]-[37] [52], where the parametric ANOVA was widely used, followed by post-hoc tests. This 
statistical test could also be applied in the works [27] [41] [45]-[47], where it was not identified which statistical method was used for data analyses. For example, ANOVA could be employed in the study performed by Granata and colleagues (1998), besides the descriptive statistics presented there. In other works [14] [23]-[26] [38] [40] [41], the tests the most adequate would be the non-parametric ones, such as Mann-Whitney and Kolmogorov-Smirnov.

\subsection{Parameters Assessed}

Khan and team (1974) as well as Ahlersova and coworkers (1981) reported that irradiation causes an increase in muscle glycogen concentration. Khan and team (1974) thought that this increase in glycogen content would be the result of the effect of radiation directly on biochemical pathways, but did not provide experimental support corroborating these findings, although Gerstner and colleagues (1953) had already pointed out changes in cell metabolism due to irradiation. However, Ahlersova, and coworkers (1981) reported that in the period immediately after irradiation, until the sixth hour following, there is a decrease in the concentration of glycogen and only the third day post-irradiation there is an increase of this polysaccharide.

Three others studies [23] [27] [39] also identified changes in metabolism involving degradation of essential proteins for structure and muscle functional performance, which led to increased availability of amino acids. Also cited in the study conducted by Gillette and coworkers (1995) [53], induced changes in the protein metabolism appear immediately after irradiation and can be the cause of myopathy associated with radiation.

Another radio-induced molecular biological endpoint is related to the structure of the sarcoplasmic reticulum membrane due to changes in the enzyme $\mathrm{Ca}^{2+}$-ATPase. These events interfere in the lipid-protein interactions, which are essential for the functional activity of this enzyme. A study [22] concerning molecular analyses within $24 \mathrm{~h}$ post-irradiation [41], it was observed a significant rise of the resting cytoplasmic $\mathrm{Ca}^{2+}$ and a reduction in the depolarization-evoked $\mathrm{Ca}^{2+}$ released from the sarcoplasmic reticulum, suggesting the correlation of these results with the potential functional changes in the muscle excitation-contraction coupling.

On the other hand, the influence of irradiation on satellite cells, that are directly responsible for tissue maintaining, was well discussed by Jurdana (2008), who also evidenced the radiation damage on proliferation capacity of these cells [36]. In this same perspective, three studies [19] [29] [30] reported that gamma radiation precludes the formation of new fibers and the use of strategies in order to increase the concentration of nitric oxide (NO) can rescue the proliferation of satellite cells after irradiation.

Gillette and colleagues (1995) reported several studies in different animal species, where muscle atrophy and fibrosis appeared after a few months of the application of the dose, always accompanied by vascular lesions. The appearance of this type of sequel in humans has also been mentioned, but there is no direct cause-effect relationship between both.

Works of Lefaix and collaborators (1990, 1993) and Ibarrola and coworkers (1996) found atrophy and fibrosis formation few months after irradiation due to the increase in non-collagenous protein synthesis by irradiated tissue, where the muscle tissue was replaced by atrophic fibrosis characterized by a high density of myofibroblasts. The intensity of fibrosis appears to be related to the increase of the applied dose.

In the work of the van Leeuwen-Segarceanu [52] carried out in human, patients previously treated by mantle field radiotherapy develop severe atrophy and weakness of the neck muscles. They concluded that neck muscles within the radiation field shows mostly myogenic damage, and muscles outside the mantle field show mostly neurogenic damage. The discrepancy between echo intensity and atrophy suggests that muscle damage is most likely caused by an extrinsic factor such as progressive microvascular fibrosis.

Still regarding the influence of irradiation on the regeneration of muscle fibers was treated in seven studies [20] [24] [25] [32] [35] [47] [48] and that five affirm to have achieved stimulate regeneration using low doses (less than 30Gy) during application or by the application of laser after irradiation. Granata and collaborators (1995) however say that irradiation reduces the growth and regeneration of muscle fibers, going against the others. On the other hand, Rosenblatt and Parry (1993) affirmed that function is unaffected of the satellite cells by ionizing radiation.

Olivé and colleagues (1995) investigated the effect of radiation in the muscle developing, concluding that cell death occurs by apoptosis. A marked increase in the number of dead cells was observed in newborn rats 6 hours after irradiation, indicating that the developing skeletal muscle is highly sensitive to ionizing radiation. A marked increase in the number of proliferating cells happened 5 days post irradiation, above normal values, thus 
indicating a high regenerative capacity of muscle developing after exposure to ionizing radiation. However, irreparable injury in muscle tissue were observed by Hsu and coworkers (1998), resulting from high doses that caused progressive structural changes.

Checking the effect of a protein as the plasma membrane element repairer, Hino and coworkers (2009) evaluated the effect of dysferlin in the repair of the plasmatic membrane and found that this protein is responsible for membrane fusion in the cure process. Meanwhile, Bandstra and collaborators (2009) observed that the irradiated muscle showed significantly lower small diameter fiber number, whereas the percentage of fibers with large diameters remained unchanged and suggest the need for others studies to investigate the mechanisms of these changes and thus have a better understanding of the effect of radiation on muscle function.

Hardee and colleagues (2014) demonstrated that dose dependent radiation-induced muscle remodeling related to expansion of the extracellular matrix and oxidative stress and the effect of radiation dose on myofiber size was affected by fiber type and oxidative metabolism. Type IIB glycolytic myofibers were susceptible to radiation-induced changes in myofiber size regardless of the total dose. However, type IIA oxidative myofiber size was not affected by the lower radiation dose.

It was observed by Russell and Nadine (2014) that radiation was associated with a significant decrease in tongue force production and reduced speed of tongue muscle contraction. However, contrary to the hypothesis, radiation treatment did not lead to muscle atrophy and fibrosis formation on tongue muscle. Thus, radiation appeared to exacerbate age-related changes in temporal factors of tongue muscle contraction.

McDonald and coworkers (2014) concluded that the extraocular muscle is spared in muscular dystrophy due to a population of myogenic precursor cells highly proliferative or better able to survive in the diseased environment of a dystrophic muscle. Alterations in myogenic precursor cell proliferation resulted in altered levels of specific subpopulations of myogenic precursor cells and the appearance of a dystrophic phenotype in the extraocular muscle of the mice mdx.

\section{Final Considerations}

Investigating the interest in the effects of ionizing radiation on the skeletal muscle, this review revealed the existence of temporal and methodological lacunae concerning this research theme.

Although six studies [21] [32] [45] [46] [49] [52] investigated the late effects of ionizing radiation on the skeletal muscle, only two [21] [52] evaluated the late radio induced changes in of mechanical proprieties on skeletal muscle used specific tests. The other studies were limited to observing the growth, regenerative capacity and sequelae of this tissue without more deep investigation about the consequences of irradiation of muscles.

With the increasing in the number of survivors of childhood cancer, the evolution of treatment with ionizing radiation, together with the aging of the world's population, long-term health effects have become a focus of medical research and care. As a result, studies about late effects of radiation on the molecular structures, mechanical properties and physiology of skeletal muscle, especially regarding the generation of force (essential feature for maintaining mobility), can provide new medical strategies to prevent complications, allowing functional independence and maintaining quality of life.

On the basis of this review and taking into account that today's technological advances make possible experiments fitted to investigate better properties of muscle tissue long after radiation exposure, a vast field of research is open concerning the late effects of irradiation of the skeletal muscle in humans.

\section{References}

[1] USA/NTP (2011) Ionizing Radiation: X-Radiation and Gamma Radiation. Report on Carcinogens. 12th Edition, North Carolina.

[2] Azevedo, A.C.P. (2009) Radioproteção em Serviços de Saúde. FIOCRUZ Escola Nacional de Saúde Pública-CESTEH, Rio de Janeiro.

[3] Oliveira, T. (2007) A importância do acompanhamento nutricional para pacientes com câncer. Prática Hospitalar, 51, $150-154$

[4] Brazil/INCA (2011) http://www2.inca.gov.br/wps/wcm/connect/cancer/site/tratamento

[5] Morris Jones, P.H. (1991) The Late Effects of Cancer Therapy in Childhood. British Journal of cancer, 64, 1-2. http://dx.doi.org/10.1038/bjc.1991.228

[6] Brazil/INCA (2010) Estimativas da incidência e mortalidade por câncer. Rio de Janeiro. 
[7] Meadows, A.T., Gallagher, J.A. and Bunin, G.R. (1992) Late Effects of Early Childhood Cancer Therapy. The British Journal of Cancer Supplement, 18, S92-S95.

[8] Flann, K.L., LaStayo, P.C., McClain, D.A., Hazel, M. and Lindstedt, S.L. (2011) Muscle Damage and Muscle Remodeling: No Pain, No Gain? The Journal of Experimental Biology, 214, 674-679. http://dx.doi.org/10.1242/jeb.050112

[9] Messina, G. and Cossu, G. (2009) The Origin of Embryonic and Fetal Myoblasts: A Role of Pax3 and Pax7. Genes \& Development, 23, 902-905. http://dx.doi.org/10.1101/gad.1797009

[10] Neumann, D.A. (2006) Cinesiologia de Aparelho Musculoesquelético: Fundamentos para Reabilitação Física. Guanabara Koogan, Rio de Janeiro, 593 p.

[11] Pratesi, A., Tarantini, F. and Di Bari, M. (2013) Skeletal Muscle: An Endocrine Organ. Clinical Cases in Mineral and Bone Metabolism, 10, 11-14. http://dx.doi.org/10.11138/ccmbm/2013.10.1.011

[12] Baar, K. and Hargreaves, M. (2011) Understanding the Regulation of Muscle Plasticity. Journal of Applied Physiology, 110, 256-257. http://dx.doi.org/10.1152/japplphysiol.01332.2010

[13] Kelencz, C.A., Munoz, I.S., Amorim, C.F. and Nicolau, R.A. (2010) Effect of Low-Power Gallium-Aluminum-Arsenium Noncoherent Light $(640 \mathrm{~nm})$ on Muscle Activity: A Clinical Study. Photomedicine and Laser Surgery, 28, 647-652. http://dx.doi.org/10.1089/pho.2008.2467

[14] Khan, M.Y. (1974) Radiation-Induced Changes in Skeletal Muscle. An Electron Microscopic Study. Journal of Neuropathology \& Experimental Neurology, 33, 42-57. http://dx.doi.org/10.1097/00005072-197401000-00004

[15] Kim, J.P., Khalmuratova, R., Jeon, S.Y., Park, J.J., Hur, D.G., Ahn, S.K., et al. (2011) Quantitative Analysis of Myosin Heavy Chain Expression Change in Laryngeal Muscle after Irradiation in Rats. Yonsei Medical Journal, 52, 158-164. http://dx.doi.org/10.3349/ymj.2011.52.1.158

[16] Leal Junior, E.C., Lopes-Martins, R.A., de Almeida, P., Ramos, L., Iversen, V.V. and Bjordal, J.M. (2010) Effect of Low-Level Laser Therapy (GaAs $904 \mathrm{~nm}$ ) in Skeletal Muscle Fatigue and Biochemical Markers of Muscle Damage in Rats. European Journal of Applied Physiology, 108, 1083-1088. http://dx.doi.org/10.1007/s00421-009-1321-1

[17] Jurdana, M. (2008) Radiation Effects on Skeletal Muscle. Radiology and Oncology, 42, 15-22. http://dx.doi.org/10.2478/v10019-007-0034-5

[18] Hardee, J.P., Puppa, M.J., Fix, D.K., Gao, S., Hetzler, K.L., Bateman, T.A., et al. (2014) The Effect of Radiation Dose on Mouse Skeletal Muscle Remodeling. Radiology and Oncology, 48, 247-256. http://dx.doi.org/10.2478/raon-2014-0025

[19] Phelan, J.N. and Gonyea, W.J. (1997) Effect of Radiation on Satellite Cell Activity and Protein Expression in Overloaded Mammalian Skeletal Muscle. The Anatomical Record, 247, 179-188. http://dx.doi.org/10.1002/(SICI)1097-0185(199702)247:2<179::AID-AR4>3.0.CO;2-T

[20] Rosenblatt, J.D. and Parry, D.J. (1992) Gamma Irradiation Prevents Compensatory Hypertrophy of Overloaded Mouse Extensor Digitorum Longus Muscle. Journal of Applied Physiology, 73, 2538-2543.

[21] Russell, J.A. and Connor, N.P. (2014) Effects of Age and Radiation Treatment on Function of Extrinsic Tongue Muscles. Radiation Oncology, 9, 254. http://dx.doi.org/10.1186/s13014-014-0254-y

[22] Shtifman, A., Pezone, M.J., Sasi, S.P., Agarwal, A., Gee, H., Song, J., et al. (2013) Divergent Modification of Low-Dose ${ }^{56} \mathrm{Fe}-$ Particle and Proton Radiation on Skeletal Muscle. Radiation Research, 180, 455-464. http://dx.doi.org/10.1667/RR3329.1

[23] Horowits, R., Kempner, E.S., Bisher, M.E. and Podolsky, R.J. (1986) A Physiological Role for Titin and Nebulin in Skeletal Muscle. Nature, 323, 160-164. http://dx.doi.org/10.1038/323160a0

[24] Popova, M.F. and Il'iasova, S.G. (1978) Vliianie luchei gelii-neonovogo lazera na protsess regeneratsii obluchennoi transplantirovannoi skeletnoi myshtsy (Effect of a Helium-Neon Laser Beam on Regeneration of Irradiated Transplanted Skeletal Muscle). Bulletin of Experimental Biology and Medicine, 86, 64-67.

[25] Wirtz, P., Loermans, H. and Rutten, E. (1982) Effects of Irradiation on Regeneration in Dystrophic Mouse Leg Muscles. British Journal of Experimental Pathology, 63, 671-679.

[26] Lefaix, J.L., Daburon, F., Martin, M. and Remy, J. (1990) Irradiation gamma et effets tardifs: La fibrose musculaire. fre. (Gamma Irradiation and Delayed Effects: Muscular Fibrosis). Pathologie Biologie, 38, 617-625.

[27] Fox Jr., J.B., Lakritz, L. and Thayer, D.W. (1993) Effect of Reductant Level in Skeletal Muscle and Liver on the Rate of Loss of Thiamin Due to Gamma-Radiation. International Journal of Radiation Biology, 64, 305-309. http://dx.doi.org/10.1080/09553009314551451

[28] Bandstra, E.R., Thompson, R.W., Nelson, G.A., Willey, J.S., Judex, S., Cairns, M.A., et al. (2009) Musculoskeletal Changes in Mice from 20-50 cGy of Simulated Galactic Cosmic Rays. Radiation Research, 172, 21-29. 
http://dx.doi.org/10.1667/RR1509.1

[29] Caiozzo, V.J., Giedzinski, E., Baker, M., Suarez, T., Izadi, A., Lan, M., et al. (2010) The Radiosensitivity of Satellite Cells: Cell Cycle Regulation, Apoptosis and Oxidative Stress. Radiation Research, 174, 582-589. http://dx.doi.org/10.1667/RR2190.1

[30] Cho-Lim, J.J., Caiozzo, V.J., Tseng, B.P., Giedzinski, E., Baker, M.J. and Limoli, C.L. (2011) Satellite Cells Say NO to Radiation. Radiation Research, 175, 561-568. http://dx.doi.org/10.1667/RR2453.1

[31] Gerstner, H.B., Lewis, R.B. and Richey, E.O. (1953) Early Effects of High Intensity X-Radiation on Skeletal Muscle. The Journal of General Physiology, 37, 445-459. http://dx.doi.org/10.1085/jgp.37.4.445

[32] Granata, A.L., Vecchi, C., Graciotti, L., Fulgenzi, G., Maggi, S. and Corsi, A. (1998) Gamma Irradiation Can Reduce Muscle Damage in mdx Dystrophic Mice. Acta Neuropathologica, 96, 564-568. http://dx.doi.org/10.1007/s004010050936

[33] Hino, M., Hamada, N., Tajika, Y., Funayama, T., Morimura, Y., Sakashita, T., et al. (2009) Insufficient Membrane Fusion in Dysferlin-Deficient Muscle Fibers after Heavy-Ion Irradiation. Cell Structure and Function, 34, 11-15. http://dx.doi.org/10.1247/csf.08033

[34] Olivé, M., Blanco, R., Rivera, R., Cinos, C. and Ferrer, I. (1995) Cell Death Induced by Gamma Irradiation of Developing Skeletal Muscle. Journal of Anatomy, 187, 127-132.

[35] Wernig, A., Zweyer, M. and Irintchev, A. (2000) Function of Skeletal Muscle Tissue Formed after Myoblast Transplantation into Irradiated Mouse Muscles. The Journal of Physiology, 522, 333-345. http://dx.doi.org/10.1111/j.1469-7793.2000.t01-2-00333.x

[36] Jurdana, M., Cemazar, M., Pegan, K. and Mars, T. (2013) Effect of Ionizing Radiation on Human Skeletal Muscle Precursor Cells. Radiology and Oncology, 47, 376-381. http://dx.doi.org/10.2478/raon-2013-0058

[37] Rosenblatt, J.D. and Parry, D.J. (1993) Adaptation of Rat Extensor Digitorum Longus Muscle to Gamma Irradiation and Overload. Pflügers Archiv, 423, 255-264. http://dx.doi.org/10.1007/BF00374404

[38] Khizhniak, S.V., Voitsitskii, V.M., Ostapchenko, S.G. and Kucherenko, N.E. (1990) Vliianie ioniziruiushchei radiatsii na aktivnost' $\mathrm{Ca}^{2+}$-ATP-azy sarkoplazmaticheskogo retikuluma skeletnykh myshts krolika. Rus. (The Effect of Ionizing Radiation on $\mathrm{Ca}^{2+}$-ATPase Activity from the Sarcoplasmic Reticulum of Rabbit Skeletal Muscles). Ukrainskii Biokhimicheskii Zhurnal, 62, 58-63.

[39] Schwenen, M., Altman, K.I. and Schroder, W. (1989) Radiation-Induced Increase in the Release of Amino Acids by Isolated, Perfused Skeletal Muscle. International Journal of Radiation Biology, 55, 257-269. http://dx.doi.org/10.1080/09553008914550291

[40] Voitsitskii, V.M., Fedorov, A.N., Lugovskii, E.B., Derzskaia, S.G., Khizhniak, S.V., Kurskii, M.D., et al. (1990) Vliianie ioniziruiushchei radiatsii na strukturu gidrofobnogo fragmenta Ca-ATFazy sarkoplazmaticheskogo retikuluma skeletnykh myshts. rus. (The Effect of Ionizing Radiation on the Structure of the Hydrophobic Fragment of Ca-ATPase in Skeletal Muscle Sarcoplasmic Reticulum). Radiobiologia, 30, 16-19.

[41] Ahlersova, E., Ahlers, I., Slavkovska, E. and Praslicka, M. (1981) Metabolic Changes after Non-Lethal X-Irradiation of Rats. I. Carbohydrates, Hormones. Folia Biologica, 27, 404-412.

[42] Khizhniak, S.V., Voitsitskii, V.M. and Kucherenko, N.E. (1991) Strukturnye izmeneniia membran sarkoplazmaticheskogo retikuluma skeletnykh myshts na rannem etape rentgenovskogo oblucheniia. rus. (Structural Changes in the Sarcoplasmic Reticulum Membrane of Skeletal Muscles at the Early Stage of X-Ray Irradiation). Ukrainskii Biokhimicheskii Zhurnal, 63, 113-117.

[43] Tatsumi, R., Liu, X., Pulido, A., Morales, M., Sakata, T., Dial, S., et al. (2006) Satellite Cell Activation in Stretched Skeletal Muscle and the Role of Nitric Oxide and Hepatocyte Growth Factor. American Journal of Physiology-Cell Physiology, 290, C1487-C1494. http://dx.doi.org/10.1152/ajpcell.00513.2005

[44] McDonald, A.A., Kunz, M.D. and McLoon, L.K. (2014) Dystrophic Changes in Extraocular Muscles after Gamma Irradiation in $m d x$ :utrophin(+/-) Mice. PLoS ONE, 9, e86424. http://dx.doi.org/10.1371/journal.pone.0086424

[45] Lefaix, J.L., Martin, M., Tricaud, Y. and Daburon, F. (1993) Muscular Fibrosis Induced after Pig Skin Irradiation with Single Doses of 192Ir Gamma-Rays. The British Journal of Radiology, 66, 537-544. http://dx.doi.org/10.1259/0007-1285-66-786-537

[46] Ibarrola, D., Francois-Joubert, A., Leviel, J.L., Massarelli, R. and Lefaix, J.L. (1996) In Vivo Study of Rabbit Irradiated Skeletal Muscle by MRI-A Long-Term Follow-Up. The British Journal of Radiology, 69, 1026-1031. http://dx.doi.org/10.1259/0007-1285-69-827-1026

[47] Popova, M.F., Buliakova, N.V. and Azarova, V.S. (1988) Tkanevye vzaimodeistviia regeneriruiushchei myshechnoi tkani v usloviiakh deistviia ioniziruiushchei radiatsii. rus. (Tissue Interactions of Regenerating Muscle Tissue with Skeletal Muscle under the Effect of Ionizing Radiation. Archives of Anatomy, Histology and Embryology, 95, 35-40.

[48] Gulati, A.K. (1987) The Effect of X-Irradiation on Skeletal Muscle Regeneration in the Adult Rat. Journal of the Neu- 
rological Sciences, 78, 111-120. http://dx.doi.org/10.1016/0022-510X(87)90083-9

[49] Hsu, H.Y., Chai, C.Y. and Lee, M.S. (1998) Radiation-Induced Muscle Damage in Rats after Fractionated High-Dose Irradiation. Radiation Research, 149, 482-486. http://dx.doi.org/10.2307/3579788

[50] Andreollo, N.A., Santos, E.F., Araujo, M.R. and Lopes, L.R. (2012) Rat's Age versus Human's Age: What Is the Relationship? Arquivos Brasileiros de Cirurgia Digestiva, 25, 49-51. http://dx.doi.org/10.1590/S0102-67202012000100011

[51] Quinn, R. (2005) Comparing Rat's to Human's Age: How Old Is My Rat in People Years? Nutrition, 21, 775-777. http://dx.doi.org/10.1016/j.nut.2005.04.002

[52] van Leeuwen-Segarceanu, E.M., Dorresteijn, L.D., Pillen, S., Biesma, D.H., Vogels, O.J. and van Alfen, N. (2012) Progressive Muscle Atrophy and Weakness after Treatment by Mantle Field Radiotherapy in Hodgkin Lymphoma Survivors. International Journal of Radiation Oncology *Biology* Physics, 82, 612-618. http://dx.doi.org/10.1016/j.ijrobp.2010.11.064

[53] Gillette, E.L., Mahler, P.A., Powers, B.E., Gillette, S.M. and Vujaskovic, Z. (1995) Late Radiation Injury to Muscle and Peripheral Nerves. International Journal of Radiation Oncology *Biology* Physics, 31, 1309-1318. http://dx.doi.org/10.1016/0360-3016(94)00422-H 